\title{
EFFECT OF COPULATION ON POTENTIALLY PRECANCEROUS PROSTATE LESIONS, SERUM TESTOSTERONE AND PROLACTIN LEVELS IN RATS
}

\author{
D. Herrera-Covarrubias ${ }^{1}$, M.B. Tecamachaltzi-Silvaran', M. Barradas-Moctezuma ${ }^{2}$, J.B. Rosales-Raya ${ }^{3}$, \\ J. Manzo ${ }^{4}$, L.I. García ${ }^{4}$, G.E. Aranda-Abreu ${ }^{4}$, N. Ismail', G.A. Coria-Avila ${ }^{4, *}$, M.E. Hernández ${ }^{4}$ \\ ${ }^{1}$ School of Psychology, University of Ottawa, Ottawa, ON K1N 6N5, Canada \\ ${ }^{2}$ Doctorate in Brain Research, University of Veracruz, Xalapa, Veracruz 91190, Mexico \\ ${ }^{3}$ Veterinary clinical laboratory, Xalapa, Veracruz 91190, Mexico \\ ${ }^{4}$ Center for Brain Research, University of Veracruz, Xalapa, Veracruz 91190, Mexico
}

\begin{abstract}
The prostate is an exocrine reproductive gland that participates in ejaculation and it is prone to diseases, including cancer. Aim: In the present study, we assessed the long-term effects of copulation on the development of precancerous lesions in rats, and compared them with testosterone-induced prostatic lesions. Materials and Methods: One group of Wistar males was given 10 copulatory sessions to one ejaculation with ovariectomized, hormone-primed females. Sessions occurred twice per week for a total of ten trials. A second group was exposed to females during the same trials, but physical contact was prevented. In addition, each group received a subcutaneous implant in the back either filled with testosterone propionate $(\mathrm{T}, 100 \mathrm{mg} / \mathrm{kg}$ ) or empty. This resulted in four subgroups: 1) Control + No sex, 2) Control + Sex, 3) $\mathrm{T}+$ No sex and 4) $\mathrm{T}+$ Sex. Two days after the $10^{\text {th }}$ trial all the males were sacrificed for prostate histology (H\&E) and hormone analysis (testosterone and prolactin). Results: Males from the group Control + No sex expressed normal histology. However, those in the groups Control + Sex and T + No sex expressed metaplasia and dysplasia in both the dorsolateral and ventral portions of the prostate, respectively. Interestingly, males from the group $\mathrm{T}+$ Sex expressed dysplasia in the dorsolateral prostate only, but not in the ventral prostate. Conclusions: These results indicate that constant copulation may facilitate the development of prostatic lesions in males with normal levels of testosterone. However, copulation induces less lesions in the ventral prostate of males treated with testosterone.
\end{abstract}

Key Words: prostate, cancer, sexual behavior, ejaculation, dysplasia, testosterone.

Prostate cancer ( $\mathrm{CaP})$ is among all types of tumors in men the second most common worldwide and every year up to $7 \%$ of all the new cases may result in death [1]. The probability to develop CaP increases with age ( $>65$ ) [2], race ( $>$ African-ancestry) [3], diet ( $>$ high-fat products) [4], obesity (body mass index $>25$ ) [5], smoking [6], and alterations in the level of hormones such as testosterone $[7,8]$ and prolactin (PRL) $[9,10]$. Consequently, efforts are made worldwide to understand its etiology and other possible contributing factors. For instance, there is no clear evidence about the role of sexual behavior in the development of precancerous and cancerous prostatic lesions, although some studies in the past argued a probable link between copulation and CaP [11-14]. For example, in the 1960's it was observed that evermarried men expressed higher mortality rates of $\mathrm{CaP}$ than single men in the United States [13]. In other studies, the number of cases of $\mathrm{CaP}$ was positively correlated with the number of sexual partners [15] and with high coital frequency [16]. Michalek et al. [17] described a probable effect of celibacy on the prevention of $\mathrm{CaP}$. They analyzed more than 1000 death certificates of Catholic clergymen in New York from

Submitted: February 04, 2016.

${ }^{\star}$ Correspondence: $\quad$ Phone: $+52-228-8418900$ EXT. 13609; Fax: +52-228-8418900 EXT. 13611; E-mail: gcoria@uv.mx

Abbreviations used: AR - androgen receptor; BHP - benign hyperplasia; CaP - prostate cancer; DLP - dorsolateral prostate; $\mathrm{N}: \mathrm{C}$ - nucleus : cytoplasm; PRL - prolactin; PRLR - prolactin receptor; s.c. - subcutaneously; $\mathrm{T}$ - testosterone; VP - ventral prostate.
1965 to 1977 and found fewer cases of CaP as compared to a matched control group of the same age. Although mortality was only $1 \%$ less in the celibate group the authors reported significant differences. However, other studies have shown either no effect of copulation on CaP or a positive effect. Kaplan [12] reported that mortality ratios of putative celibate priests resembled that of a population with a high alcohol and caloric intake but a relatively low exposure to tobacco. The study did not discard the possibility that celibacy had a protective effect for $\mathrm{CaP}$, but argued that the evidence to suggest so was too weak. More recent evidence from a study with controls and cohorts argued that copulation protects the prostate from $\mathrm{CaP}$ [14]. Such studies provide ambiguous evidence to support any hypothesis about the role of copulation on prostate health.

As mentioned above, precancerous or cancerous lesions in the prostate have also been related to abnormal levels of testosterone and PRL [7-10]. Copulation increases the levels of serum testosterone $[18,19]$ and $\operatorname{PRL}[20,21]$ in both humans and laboratory rats. In addition, ejaculation increases the levels of androgen receptors (AR) and mRNA for AR in the prostate [22]. Testosterone can induce cell division and spontaneous mutations that result in more and abnormal cells within the gland $[7,8]$. Similarly, PRL can activate molecular pathways (i.e. Jak2-Stat5a/b) that may result in tumorigenesis and progression to CaP [23]. Indeed, it has been shown that rats that receive systemic treatment with either testosterone or PRL during 4 weeks or more 
will express precancerous lesions of the prostate (i.e. dysplasia) [9]. Accordingly, copulation per se induces short-term endocrine changes that might function as a long-term risk factor for the development of precancerous lesions. However, this has not been shown experimentally in an animal model. Thus, the aim of the present study was to assess the effects of repeated copulation to ejaculation on the development of precancerous prostatic lesions (i.e. dysplasia) in adult male rats. Our first hypothesis stated that constant copulation during 5 weeks would induce histological lesions comparable to those observed in males exposed to exogenous systemic testosterone during the same period. In addition, we hypothesized that the baseline blood levels of testosterone and PRL would be higher in male rats allowed to copulate constantly.

\section{MATERIALS AND METHODS}

Animals. We used 20 Wistar males and 10 females (Rattus norvegicus albinus). They were purchased from a certified laboratory animal supplier in Mexico (Circulo ADN) and were 8 weeks old and sexually naive at the start of the study. They were group-housed in large plexiglas cages $(50 \times 30 \times 20 \mathrm{~cm})$, and kept in a colony room at the Center for Brain Research, University of Veracruz, Mexico, in a 12-12 $\mathrm{h}$ reverse Light-Dark cycle (lights off at 8:00 hrs). Water and commercial feed (Rismart rat chow) were provided ad libitum. All the experimental procedures were carried out according to the Official Mexican Norm NOM062-ZOO-1999 for use and care of laboratory animals.

Surgery and hormone treatments. One week before the start of copulatory trials all the males were randomly organized in two main groups, depending on the treatment they received at 8 weeks of age. The testosterone group ( $\mathrm{T}$ ) was implanted subcutaneously (s.c.) in the back with a silastic tube (Dow Corning Corp $25 \mathrm{~mm}$ length, $1.57 \mathrm{~mm}$ I.D. $\times 3.18 \mathrm{~mm}$ O.D.), containing solid testosterone propionate (Sigma-Aldrich). This resulted in approximately $100 \mathrm{mg} / \mathrm{kg}$ of body weight as previously used in other studies [9, 24]. A second group served as control and was exposed to the same procedures, but the silastic tube was empty. Surgical implantation was done under inhaled halothane anesthesia, and took less than 3 min for each rat. After confirmation of deep anesthesia we performed a $10 \mathrm{~mm}$ skin incision on the lower back. A surgical probe was inserted s.c. and it was moved rostrally to separate the skin from the muscle. The silastic tube was slided in and pushed up to be placed at the upper back, between the two scapulae. The lower back incision was sutured and the rat was allowed to fully recover before it was placed back into its home cage. Early studies showed that these silastic capsules release testosterone at a rate of $\sim 30 \mu \mathrm{g} / \mathrm{day} / \mathrm{cm}$ [25]. Both groups ( $T$ and Control) were further divided in two subgroups, depending on whether or not they were allowed to engage in sexual behavior to ejaculation. This resulted in four subgroups: 1) $T+$ $\operatorname{Sex}(n=5), 2) T+\operatorname{Nosex}(n=5), 3)$ Control + Sex $(n=5)$, and 4$)$ Control + No sex $(n=5)$.
The stimulus females were ovariectomized (OVX) and primed fully with s.c. injections of estradiol benzoate $(10 \mu \mathrm{g}) 48 \mathrm{~h}$ and progesterone $(500 \mu \mathrm{g}) 4 \mathrm{~h}$ before each copulatory trial. For ovariectomy, females were anesthetized with a mixture of ketamine hydrochloride $(50 \mathrm{mg} / \mathrm{ml})$ and xylazine hydrochloride $(4 \mathrm{mg} / \mathrm{ml})$, mixed at a ratio of $4: 3$, respectively, injected intraperitoneally in a volume of $1 \mathrm{ml} / \mathrm{kg}$ of body weight. Anesthetized females were then OVX bilaterally via a lumbar incision. Post-surgical treatment for females included 3 days of s.c. injections of flunixin meglumine $(2.5 \mathrm{mg} / \mathrm{kg})$ for analgesia, and enrofloxacin $(5 \mathrm{mg} / \mathrm{kg})$ every $24 \mathrm{~h}$ to prevent post-surgical bacterial infections. All females were given a week of post-surgical recovery before they were used as sexual partners.

Sexual behavior. One week after the surgical implantation of the silastic tubes ( $T$ or Control), the males started the first copulatory trial. Thus, the subgroups $\mathrm{T}+$ Sex and Control + Sex were allowed to copulate twice a week with the OVX sexually receptive female for a total of 10 trials (5 weeks of sexual activity). Subgroups $T+$ No sex and Control + No sex were also exposed to a sexually receptive female behind a wiremesh that prevented copulation, but allowed visual, olfactory and acoustic stimulation. Each copulatory trial occurred in squared chambers $(39 \times 21 \times$ $21 \mathrm{~cm}$ ) in which males were allowed to interact freely with the female until the first ejaculation was observed. Males were gently removed from the chamber one minute after ejaculation or after $60 \mathrm{~min}$ in case that ejaculation did not occur. The number of males that ejaculated in each trial and the ejaculation latency were recorded.

Prostate samples and histology. Two days after the $10^{\text {th }}$ copulatory session the rats were anesthetized with sodium pentobarbital ( $35 \mathrm{mg} / \mathrm{kg}$ intraperitoneally). Then $3 \mathrm{ml}$ of blood were obtained by cardiac puncture for hormone analysis (see Hormone measurements for further details). Anesthetized rats were then sacrificed with an overdose of sodium pentobarbital $(120 \mathrm{mg} / \mathrm{kg})$. An abdominal incision was performed and the accessory sexual organs were carefully removed and placed into a container with $0.9 \%$ saline solution. The prostate was identified under a dissecting microscope (MEJI, EMZ-TR) and the gland was further divided into ventral (VP) and dorsolateral (DLP) prostate. The VP and DLP were soaked in formol $10 \%$ during $24 \mathrm{~h}$, then dehydrated in alcohol $70 \%$ and $80 \%$ ( $1 \mathrm{~h}$ each), and $95 \%$ $(3 \times 2 \mathrm{~h}$ each), and ethanol $100 \%$ overnight, plus two more changes ( $1 \mathrm{~h}$ each), the following day. Then xylene $(3 \times 1 \mathrm{~h}$ each) was added, always with constant shaking. Tissue was embedded in paraffin wax $2 \times 2 \mathrm{~h}$ each), sliced ( $5 \mu \mathrm{m}$ thick) with a microtome (RM 2125RT Leica), mounted on slides in a bath at $52{ }^{\circ} \mathrm{C}$ (containing pork skin-based gelatin $2.5 \mathrm{mg} / 100 \mathrm{ml}$ ) and then processed for hematoxylin and eosin (H\&E) dye technique as follows: $1 \mathrm{~h}$ at $57^{\circ} \mathrm{C}$, deparaffinization in xylene $(3 \times 5 \mathrm{~min}$ each), rehydration in alcohol/xylene (1:1) $5 \mathrm{~min}$, ethanol $96 \% 3 \mathrm{~min}$, hematoxylin (10 min), water (30 s), acid alcohol (quick immersion), water (10 s), lithium carbonate 
(30 s), water (10 s), eosin (4 quick immersions), dehydration in ethanol 96\% (3 min), ethanol 100\% (2 min), ethanol/xylene 1:1 (2 min), and xylene (5 min). Then Permount was added and slides were coverslipped, air dried, and observed under a light microscope (Olympus $A \times 70$ ). Photomicrographs were taken at $40 \times$ and analyzed by the same experimenters. As in the previous study [9], we assessed prostate histology from normal to abnormal by taking into consideration the following histological features: 1) epithelium form (cubic in DLP, columnar in VP, vs hyperplasia, metaplasia, dysplasia, cancer in situ), 2) epithelium size (even vs anisocytosis), 3 ) epithelium papillae (scarce vs plenty), 4) interstice space (even vs compressed), 5) interstice content (collagen vs mononuclear), 6) nucleus size (even vs anisokariosis), 7) nucleus location (basal cell polarity vs non basal), 8) nucleus to cytoplasm ratio $\mathrm{N}: \mathrm{C}(1: 2$ vs $1: 1)$, 9) myoepithelium (euplasia vs proplasia), 10) pattern observed at $4 \times$ (tubular vs cribiform), 11) lumen content (amorphous vs granular), and 12) chromatin (heterochromatin vs euchromatin). A blind score was performed by researchers and veterinarians for each prostate sample. Accordingly, the experimenters did not know to what subgroup of rats belonged each analyzed gland at the moment of diagnosis.

Hormones measurement. The hormones testosterone and PRL were measured in blood serum exclusively two days after the $10^{\text {th }}$ copulatory session. Namely, on the same day the prostate was obtained. Blood was collected in vacutainer tubes containing no anticoagulant and incubated in upright position at room temperature for $30 \mathrm{~min}$ to allow clotting. Tubes were centrifuged for $15 \mathrm{~min}$ at 1000 r.p.m. Supernatant was aspirated at room temperature and serum was kept in $500 \mu \mathrm{l}$ aliquots and frozen at $-20{ }^{\circ} \mathrm{C}$ during few days until processing. We used an enzyme-linked immunosorbent assay (ELISA) and commercial kits for testosterone (ALPCO 11-TESHU-E01) and PRL (ALPCO 55-PRLRT-E01) and instructions were followed as indicated by the supplier. The assays were read in an IMARK microplate reader with the software microplate manager from Bio-Rad.

Variables and statistical analysis. 1) Behavior: The ejaculation latency (minutes) was analyzed with a two-way (hormone treatment x session) ANOVA. Significant differences were followed by a Fisher LSD posthoc test. The proportion of ejaculators for each session was also analyzed with a $2 \times 2$ contingency table (one-tailed Fisher exact probability test), considering the number of males that did (or did not) ejaculate. 2) Histology: We described 12 histological features in each male (See section Prostate samples and histology). 3) Hormones: Levels of testosterone and PRL $(\mathrm{ng} / \mathrm{mL})$ were analyzed with a non-parametric Kruskal - Wallis test, followed by Mann - Whitney tests to compare individual differences. All statistical analyses were performed using GraphPad Prism version 6.00 for Mac, GraphPad Software, La Jolla California USA, www.graphpad.com and the alpha level was set at $\mathrm{p}<0.05$.

\section{RESULTS}

Sexual behavior. With regard to the ejaculation latency the ANOVA failed to detect an interaction between hormone treatment $\times$ session $\mathrm{F}(9,72)=0.46$, $p<0.89$, or a main effect of treatment $F(1,8)=0.02, p<$ 0.88 , but detected a main effect of session $F(9,72)=$ $2.03, p<0.04$. The posthoc analysis, however, did not detect specific differences between sessions (Fig. 1). The analysis of the number of ejaculators showed significant differences at session 1 (ejaculation was observed in 2 control vs 8 testosterone-treated males, $p<0.01$ ), and at session 10 (ejaculation occurred in 10 control males vs 6 testosterone-treated, $\mathrm{p}<$ 0.04 ), but not at sessions $2-9$. These data indicated that rats from both groups reduced their ejaculation latency throughout the sessions. In addition, testosterone-treated males were more likely than controls to ejaculate at session 1 , but less likely at session 10 (Fig. 2).

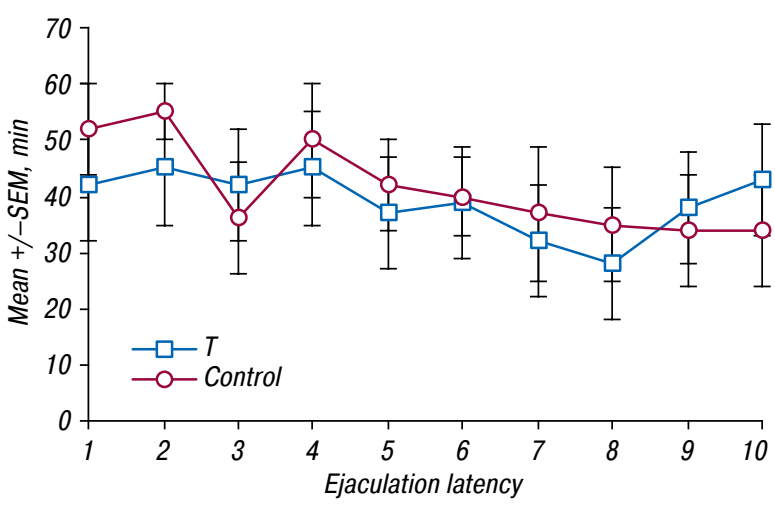

Fig. 1. The ejaculation latency (minutes) of male rats during 10 copulatory trials ( 5 weeks). Testosterone males received a subcutaneous implant in the back, filled with $100 \mathrm{mg} / \mathrm{kg}$ of testosterone propionate. Control males received an empty implant



Fig. 2. Shows the proportion of males from Fig. 1 that ejaculated in each session. * Significant differences were detected between control and testosterone males at session 1 and 10

Prostate lesions induced by copulation or testosterone. In general, the group Control + No sex expressed a normal (cubic) epithelium in the DLP, even in size (normal), with scarce papillae (normal). The interstitial space was even in size (normal) and contained collagen (normal). Interestingly, in 3 out of 5 rats the cell nuclei in the DLP were not homogeneous in size (anisokaryosis), and expressed a relation $\mathrm{N}: \mathrm{C}$ of 1:1 (normal $>1: 2$ ). Nevertheless, the nucleus had basal cell polarity (normal), the myoepithelium was euplastic (normal), with 

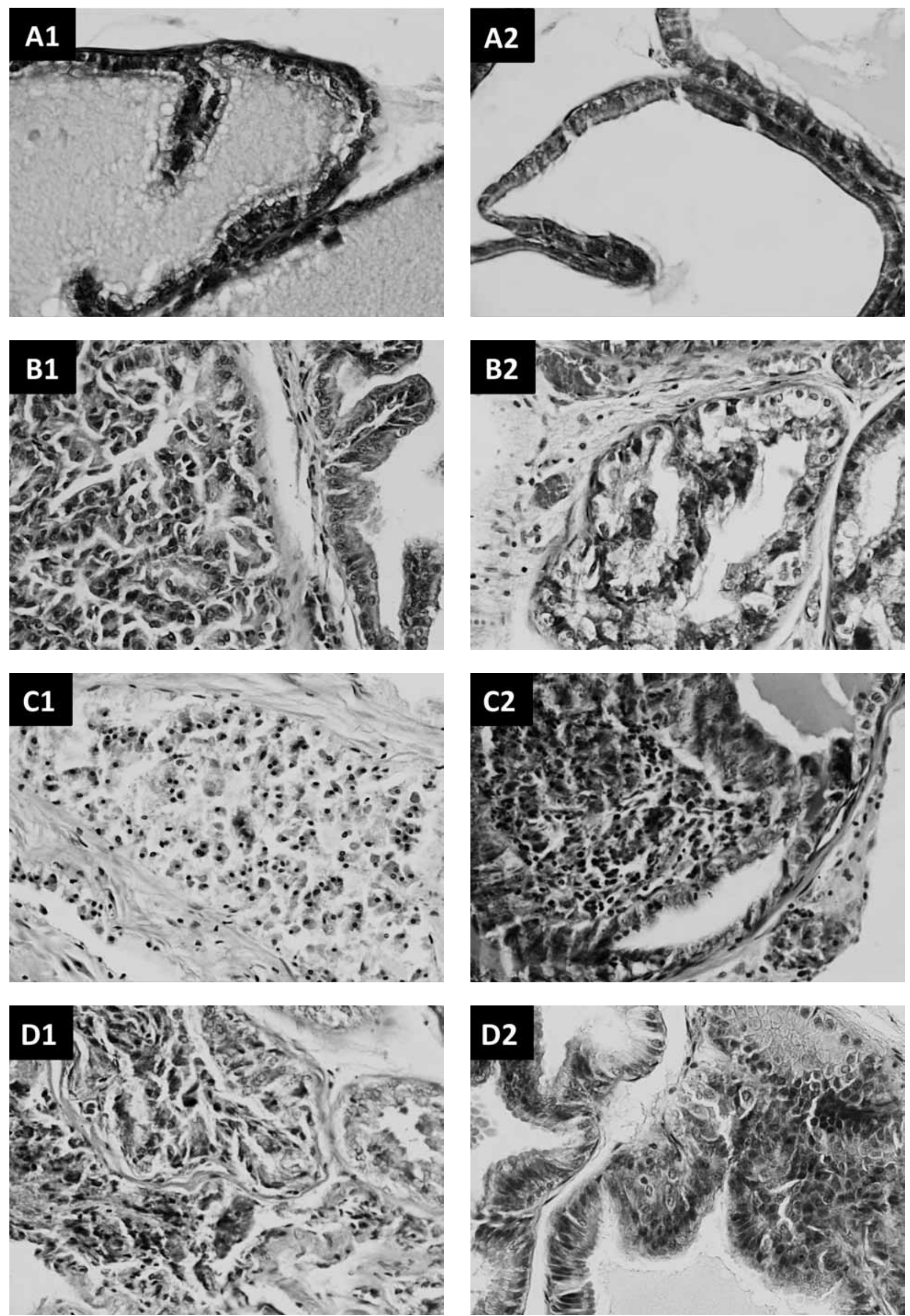

Fig. 3. DLP (1) and VP (2) of rats divided in four subgroups: $A-$ Control + No sex, $B-$ Control + Sex, $C-T+N o$ sex, $D-T+$ Sex. A1 - normal cubic epitheium (DLP), A2 - normal columnar epithelium, B1 - metaplasia, B2 - dysplasia, C1 - dysplasia, C2 - dysplasia, D1 - dysplasia, D2 - columnar 
tubular pattern (normal), amorphous content (normal), and there was heterochromatin, which is a less active form of chromatin (Fig. 3, A1). In the same group (Control + No sex) $3 / 5$ animals expressed a columnar epithelium (normal) in the VP, although some cases of anisocytosis were observed in 3/5 animals, and also expressed scarce papillae (normal). The interstitial space was even in size and contained colagen (normal). Nuclei were homogeneous in size (normal), with a basal cell polarity (normal), and a N:C of 1:2, and there was heterochromatin. The myoepithelium was euplasic and the pattern observed at $4 \times$ was tubular (Fig. 3, A2). Although males from this subgroup (Control + No sex) had in general normal histological features, none of them expressed $100 \%$ of normal histology. For example, some males with normal epithelium's form expressed what is considered abnormal epithelium's size (anisocytosis) or abnormal nucleus size (anisokaryosis), or modified $\mathrm{N}: \mathrm{C}$ ratio $(1: 1)$. This suggests that even in a sample of putative healthy rats there is variability in the histological features of the prostate.

Rats from the subgroups Control + Sex, T + Sex and $T+$ No sex displayed more histological abnormalities in both the DLP and VP. Such differences and the number of males with normal or abnormal features can be observed in Fig. 3, B, C, D, and 4, $a, b$.

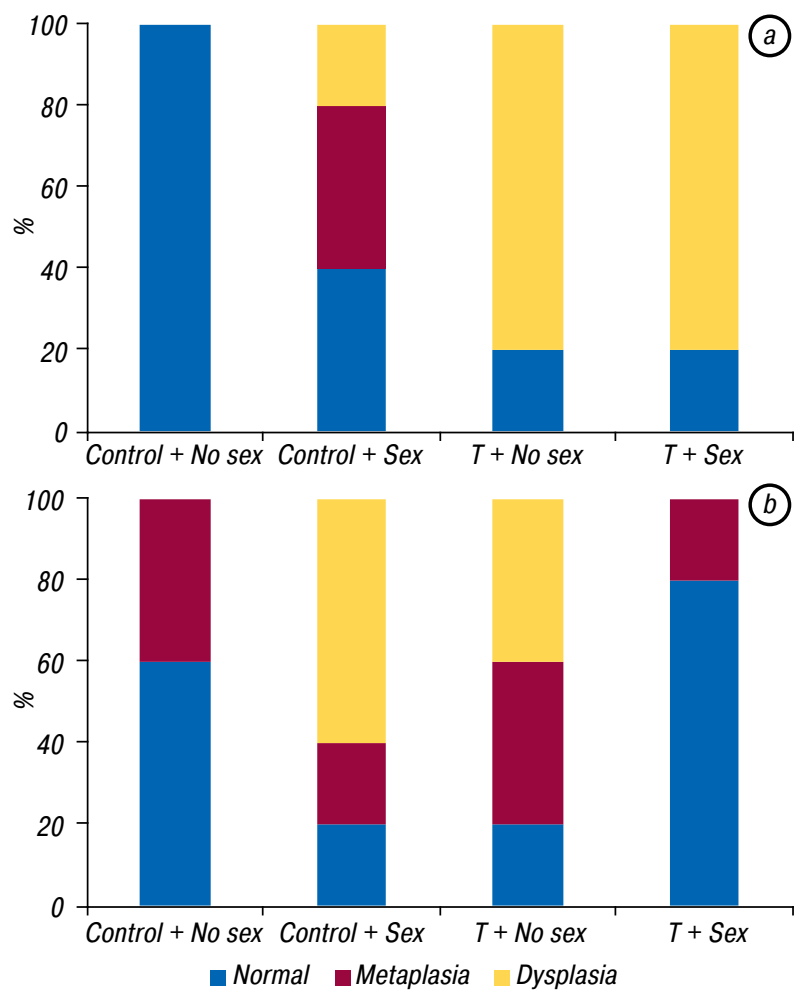

Fig. 4. Effect of constant copulation on the proportion of males with normal or abnormal epithelium in (a) the DLP and $(b)$ in VP

For instance, in the DLP the Control + Sex males displayed more cases of abnormal epithelium (must be cubic in DLP and columnar in VP), or more severely affected with dysplasia (considered precancerous). There were also cases of anisocytosis, compressed interstice, anisokaryosis, apolarity of the nucleus, proplasia of myoepithelium (enlarged), cribriform pattern, granular content in lumen, and euchromatin (more ac- tive form of chromatin). In the T + Sex and T + No sex subgroups there were more cases of epithelium dysplasia in the DLP. Interestingly, fewer cases of dysplasia were observed in the VP of T + Sex animals (Fig. 4, b).

Serum levels of testosterone and PRL. With regard to testosterone, the Kruskal - Wallis test revealed significant differences between groups $\mathrm{H}(4,19)=8.2$, $\mathrm{p}<0.05$. The Mann - Whitney test indicated individual differences between the subgroups Control + No sex $($ Median $=0.38 \mathrm{ng} / \mathrm{ml})$ vs Control + Sex $($ Median $=$ $2.05 \mathrm{ng} / \mathrm{ml}) \mathrm{U}=2, \mathrm{p}<0.05$, and between Control + Sex $($ Median $=2.05 \mathrm{ng} / \mathrm{ml})$ vs $\mathrm{T}+$ No sex $($ Median $=$ $0.21 \mathrm{ng} / \mathrm{ml}$ ) $U=1, p<0.05$ (Fig. 5). With regard to $P R L$, the analysis failed to detect significant differences between groups: Control + No sex (Median $=20.86 \mathrm{ng} / \mathrm{ml})$, Control + Sex $($ Median $=32.15 \mathrm{ng} / \mathrm{ml}), \mathrm{T}+$ No sex $(\mathrm{Me}-$ dian $=100.8 \mathrm{ng} / \mathrm{ml})$ and $\mathrm{T}+\operatorname{Sex}($ Median $=21.22 \mathrm{ng} / \mathrm{ml})$ $\mathrm{H}(4,18)=3.02, \mathrm{p}=0.37$.

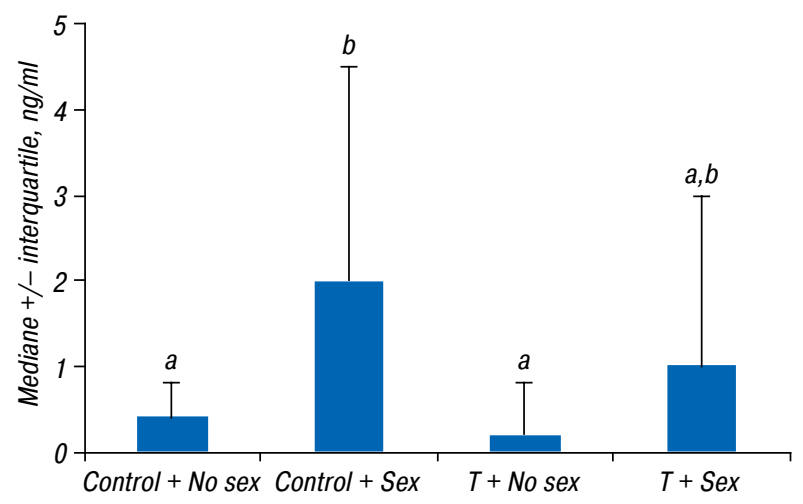

Fig. 5. Serum baseline levels of testosterone after 10 trials of copulation ( 5 weeks). Different letters indicate significant differences between bars

\section{DISCUSSION}

The results of the present study indicate that in rats repeated copulation induced histological alterations in both the DLP and VP (e.g. metaplasia and dysplasia). In the DLP the lesions were milder than those observed in sexually naïve males that received exogenous testosterone, but in the VP the effect of copulation and testosterone were comparable. Copulation plus exogenous testosterone had additional negative effects in the DLP as compared to testosterone without copulation, but in the VP such combination decreased the cases of dysplasia (see Fig. 4, $a, b$ ). The baseline levels of serum testosterone were higher in males with constant copulation, but not in males with s.c. implants filled with testosterone. We speculate that testosterone was increased during the first week of implant, but decreased subsequently via negative feedback mechanisms, resulting in low levels after 6 weeks. Such argument is possibly supported by the proportion of ejaculators observed in sessions 1 and 10 (see Fig. 2). That is, more testosterone-treated males ejaculated at session 1 as compared to control males, but the opposite outcome occurred by the $10^{\text {th }}$ session. The results also indicate that the levels of serum PRL were not affected by either copulation or testosterone implants. Thus, we argue that prostate 
lesions induced by constant copulation ( 5 weeks) are mainly due to the effects of increased testosterone.

Specific effects of copulation on prostate lesions. After 10 copulatory sessions $60 \%$ of males from the Control + Sex subgroup were affected. Two of them expressed in the DLP an epithelium with metaplasia (Fig. 3, B1) that is the reversible replacement of one differentiated cell type with another mature differentiated cell type. Those rats also expressed anisocytosis (unequal abnormal size of epithelium cells) and plenty of papillae, which resulted in reduced interstices. In addition, cells started to express abnormal nuclear shape (anisokaryosis), which is one of the key diagnostic tools used in identifying cancerous cells [26, 27]. Furthermore, the nuclei were no longer polar, the $\mathrm{N}: \mathrm{C}$ ratio was abnormal (1:1) and there was a cribriform pattern. Anysokaryosis, apolarity and alterations in $\mathrm{N}: \mathrm{C}$ indicate changes in chromosome organization, which in turn can affect gene expression [28] that eventually may result in dysplasia (observed in one male). In the subgroups $T$ + No sexand $T+\operatorname{Sex} 80 \%$ of the rats expressed dysplasia in the DLP (Fig. 3, C1, D1), which refers to a precancerous lesion characterized by the presence of immature and abnormal epithelial cells with abnormal function. These changes indicate that in the DLP s.c. implants of testosterone $(100 \mathrm{mg} / \mathrm{kg})$ for periods as short as 5 weeks are more aggressive than the effects of copulation during the same period. Further experiments are required to confirm that testosterone is the only responsible of copulationinduced prostatic lesions. In addition, it is important to figure out if a long resting period after constant copulation would result in a total recovery of the prostate.

Effects of copulation and testosterone on DLP and VP. As mentioned above, copulation affected the DLP and the combination of copulation plus exogenous testosterone resulted in more alterations. Males from the $T+$ Sex subgroup expressed more cases of anisocytosis, proplastic myoepithelium and apolar nuclei than males from the $T+$ No sex subgroup. However, this was not observed in the VP. As a matter of fact, copulation plus exogenous testosterone resulted in fewer cases of dysplasia in the VP (see Fig. $4, b$ ). Evidence indicates that ejaculation induces in the VP an acute increase in the levels of both AR and AR-mRNA [22]. However, it is not known whether such increase is maintained after 5 weeks of constant copulation in rats. One speculation is that the opposite occurs after several copulatory trials, namely that AR may be decreased and therefore VP may be less sensitive to exogenous testosterone. Like in rats, the human prostate is also heterogeneous with regard to its embryologic origin and histology [29]. Its three zones (periurethral, central and peripheral) contain different concentration of glands, conducts, and AR distribution as observed in cases of CaP [30]. Such heterogeneity may account for the different effects of copulation on prostatic lesions in humans.

Copulation affected both portions of the prostate (DLP and VP) of control males, but prevented dysplasia in the VP of those males that received exogenous testosterone. Accordingly, the frequency of copulation plus the levels of serum testosterone may help to account the probability of prostatic lesions in VP of rats or in homologous prostatic areas in other species. For example, age $65+$ is a risk factor to develop CaP in humans. At that age the blood levels of testosterone are decreased by more than $50 \%$ in some men [31-34]. Human prostatic areas homologous of rat VP should be more sensitivity to copulation-induced testosterone, which would result in higher risk of $\mathrm{CaP}$ in low-testosterone men. By contrast, the same homologous areas of men with higher levels of testosterone should be benefited by copulation. Indeed, recent evidence from a study with controls and cohorts for CaP showed a protective effect of copulation, which also correlated with higher levels of serum testosterone in the controls [14]. Some of the mechanisms to explain the effect of copulation on DLP and VP may involve the AR directly [35]. It remains to be shown whether the AR gene may mutate or be amplified by repeated copulation so that the AR may respond to lower levels of androgens, or perhaps to other hormones (i.e. PRL) [10, 36-38].

\section{CONCLUSIONS}

Either constant copulation or exogenous testosterone resulted in histological alterations of the two prostatic portions (DLP, VP) in rats. However, the combination of copulation plus exogenous testosterone affected mainly the DLP, and to a much less extent the VP. This suggests a bimodal effect of copulation in the VP, depending on the levels of serum testosterone. Accordingly, the celibacy theory may be supported in males with normal or low levels of testosterone, but would not be supported in males with higher-than-normal levels of testosterone. Further research is needed for understanding the specific role of copulation at long-term on the levels of AR in the VP and the development and maintenance of prostatic diseases, including cancer $[39,40]$.

\section{ACKNOWLEDGMENTS}

This study was supported by Consejo Nacional de Ciencia y Tecnología (CONACYT) from Mexico, with a postdoctoral fellowship to DHC (No. 250561), and to GACA (No. CB-167773). The authors want to give special thanks to Rodrigo Ramírez-Rodríguez for helping with animals and samples handling.

\section{CONFLICTS OF INTEREST}

The authors declare that they have no conflict of interest.

\section{REFERENCE}

1. Ferlay J, Soerjomataram I, Ervik M, et al. Cancer incidence and mortality worldwide: IARC Cancer Base 2013, GLOBOCAN: http: \\globocan.iarc.fr.

2. Williams TH. Occult carcinoma and benign hypertrophy of the prostate in men over fifty years of age. Treat Serv Bull 1954; 9: 201-16.

3. Allott EH, Howard LE, Song HJ, et al. Racial differences in adipose tissue distribution and risk of aggressive prostate cancer among men undergoing radiation therapy. Cancer Epidemiol Biomarkers Prev 2014; 23: 2404-12.

4. Chang SN, Han J, Abdelkader TS, et al. High animal fat intake enhances prostate cancer progression and reduces 
glutathione peroxidase 3 expression in early stages of TRAMP mice. Prostate 2014; 74: 1266-77.

5. Haque R, Van Den Eeden SK, Wallner LP, et al. Association of body mass index and prostate cancer mortality. Obes Res Clin Pract 2014; 8: e374-81.

6. Roman MD, Niclis C, Tumas N, et al. Tobacco smoking patterns and differential food effects on prostate and breast cancers among smokers and nonsmokers in Cordoba, Argentina. Eur J Cancer Prev 2014; 23: 310-8.

7. Agoulnik IU, Krause WC, Bingman WE, et al. Repressors of androgen and progesterone receptor action. J Biol Chem 2003; 278: 31136-48.

8. Noble RL. Sex steroids as a cause of adenocarcinoma of the dorsal prostate in $\mathrm{Nb}$ rats, and their influence on the growth of transplants. Oncology 1977; 34: 138-41.

9. Herrera-Covarrubias D, Coria-Avila GA, ChavarriaXicotencatl $\mathrm{P}$, et al. Long-term administration of prolactin or testosterone induced similar precancerous prostate lesions in rats. Exp Oncol 2015; 37: 13-8.

10. Mearini L, Zucchi A, Nunzi E, et al. Low serum testosterone levels are predictive of prostate cancer. World $\mathrm{J}$ Urol 2013; 31: 247-52.

11. Dimitropoulou $P$, Lophatananon $A$, Easton $D$, et al. Sexual activity and prostate cancer risk in men diagnosed at a younger age. BJU Int 2009; 103: 178-85.

12. Kaplan SD. Retrospective cohort mortality study of Roman Catholic priests. Prev Med 1988; 17: 335-43.

13. King H, Diamond E, Lilieneld AM. Some epidemiological aspects of cancer of the prostate. J Chronic Dis 1963; 16: $117-53$

14. Ahmadi $\mathrm{H}$, Allameh $\mathrm{F}$, Baradaran $\mathrm{N}$, et al. Circulating sex hormones play no role in the association between sexual activity and the risk of prostate cancer. J Sex Med 2011; 8: 905-13.

15. Steele R, Lees RE, Kraus AS, et al. Sexual factors in the epidemiology of cancer of the prostate. J Chronic Dis 1971; 24: 29-37.

16. Krain LS. Epidemiologic variables in prostatic cancer. Geriatrics 1973; 28: 93-8.

17. Michalek AM, Mettlin C, Priore RL. Prostate cancer mortality among Catholic priests. J Surg Oncol 1981; 17: $129-33$.

18. Graham JM, Desjardins C. Classical conditioning: induction of luteinizing hormone and testosterone secretion in anticipation of sexual activity. Science 1980; 210: 1039-41.

19. Fox CA, Ismail AA, Love DN, et al. Studies on the relationship between plasma testosterone levels and human sexual activity. J Endocrinol 1972; 52: 51-8.

20. Hernandez ME, Soto-Cid A, Rojas F, et al. Prostate response to prolactin in sexually active male rats. Reprod Biol Endocrinol 2006; 4: 28.

21. Kruger TH, Haake $P$, Hartmann U, et al. Orgasminduced prolactin secretion: feedback control of sexual drive? Neurosci Biobehav Rev 2002; 26: 31-44.

22. Hernandez ME, Soto-Cid A, Aranda-Abreu GE, et al. A study of the prostate, androgens and sexual activity of male rats. Reprod Biol Endocrinol 2007; 5: 11.
23. Goffin V, Hoang DT, Bogorad RL, et al. Prolactin regulation of the prostate gland: a female player in a male game. Nat Rev Urol 2011; 8: 597-607.

24. Antonio-Cabrera E, Paredes RG. Effects of chronic estradiol or testosterone treatment upon sexual behavior in sexually sluggish male rats. Pharmacol Biochem Behav 2012; 101: 336-41.

25. Stratton LG, Ewing LL, Desjardins C. Efficacy of testosterone-filled polydimethylsiloxane implants in maintaining plasma testosterone in rabbits. J Reprod Fertil 1973; 35: 235-44.

26. Webster M, Witkin KL, Cohen-Fix O. Sizing up the nucleus: nuclear shape, size and nuclear-envelope assembly. J Cell Sci 2009; 122: 1477-86.

27. Zink D, Fischer AH, Nickerson JA. Nuclear structure in cancer cells. Nat Rev Cancer 2004; 4: 677-87.

28. He S, Dunn KL, Espino PS, et al. Chromatin organization and nuclear microenvironments in cancer cells. J Cell Biochem 2008; 104: 2004-15.

29. Lee CH, Akin-Olugbade O, Kirschenbaum A. Overview of prostate anatomy, histology, and pathology. Endocrinol Metab Clin North Am 2011; 40: 565-75, viii-ix.

30. Pertschuk LP, Zava DT, Gaetjens E, et al. Detection of androgen and estrogen receptors in human prostatic carcinoma and hyperplasia by fluorescence microscopy. Res Commun Chem Pathol Pharmacol 1978; 22: 427-30.

31. Gray A, Feldman HA, McKinlay JB, et al. Age, disease, and changing sex hormone levels in middle-aged men: results of the Massachusetts Male Aging Study. J Clin Endocrinol Metab 1991; 73: 1016-25.

32. Harman SM, Metter EJ, Tobin JD, et al. Longitudinal effects of aging on serum total and free testosterone levels in healthy men. Baltimore Longitudinal Study of Aging. J Clin Endocrinol Metab 2001; 86: 724-31.

33. Araujo AB, Esche GR, Kupelian V, et al. Prevalence of symptomatic androgen deficiency in men. J Clin Endocrinol Metab 2007; 92: 4241-7.

34. Wu FC, Tajar A, Pye SR, et al. Hypothalamic-pituitary-testicular axis disruptions in older men are differentially linked to age and modifiable risk factors: the European Male Aging Study. J Clin Endocrinol Metab 2008; 93: 2737-45.

35. Grossmann ME, Huang H, Tindall DJ. Androgen receptor signaling in androgen-refractory prostate cancer. J Natl Cancer Inst 2001; 93: 1687-97.

36. Webber M. Polypeptide hormones and the prostate. In: The prostate cell: structure and function. GP Murphy, AA Sandberg, JP Karr, eds. Alan R. Liss: New York, 1981.

37. Harper ME, Peeling WB, Cowley T, et al. Plasma steroids. Acta Endocrinol 1976; 81: 409-26.

38. Saroff J, Kirdoni RY, Chu TM, et al. Measurements of prolactin and androgens in patients with prostatic disease. Oncology 1980; 37: 46-52.

39. Walker AM. Prolactin receptor antagonists. Curr Opin Investig Drugs 2005; 6: 378-85.

40. Gonzalez-Lucano LR, Munoz-Valle JF, AscencioCedillo R, et al. Increased expression of the prolactin receptor is associated with malignant laryngeal tumors. Exp Ther Med 2012; 3: 603-7. 